\title{
Conceptualizing Globalization
}

\author{
Sulayman Nyang
}

The term globe in the English language enjoys the same meaning as the English word world. The term globalization is now used to denote a trend in world affairs in which several factors and forces impact on the way we view ourselves, our world, societies, cultures, the physical world, and the rest of the universe. The Arabic word for this geographic world is 'älam; hence, the Qur'anic usage describing the Creator as Rabb al 'Álamin (The Lord of the Worlds). This Islamic term conjures up an image that cuts across the vast range of beings and their domains of existence in creation.

The understanding of globalization that is beginning to gain acceptance throughout the world centers on the hegemony of the mass media in the realm of human consciousness. To put the matter humorously, one can say that the electron has now become the secret mediator between people located in one part of the world and their counterparts located elsewhere on the globe. It was this image that led the late Marshall MacLuhan to use the metaphor of the tele-village to describe what he believed was happening in the area of human communications.

Globalization now manifests itself in five important ways. The first involves the shortening of geographic distances and the ease of human travel via faster means of locomotion, such as supersonic planes, nuclear-powered ships, high-speed cars, and bullet trains. These modern means of travel have combined to create a new world order for humanity. The world is no longer a wild place where humans must battle with other zoological rivals; rather, it has become a place where human creativity and power now reign supreme, if matters are seen through the eyes of nonhuman flora and fauna.

The second manner in which globalization is shaping our world is in the traversing of physical distances through the effective manipulation of the electron in the service of humanity. By virtue of humanity's scientific 
and technological development, people now commonly cross vast distances by telephone, fax, telex, and e-mail. All of these inventions, which did not exist just a hundred years ago, have become part of the growing arsenal of human society in the process of globalization.

The third manifestation is seen in the emergence of a world culture driven by the following universalizing factors: the growing impact of English as a common lingua franca, the integration of almost all societies and cultures into the world economy, the universalizing tendencies of science and technology, and the gradual emergence of a world moral order whose building blocs are drawn from humanity's religious and secular heritages.

The fourth manifestation is the homogenization of human societies, a trend that has been facilitated by the universal adoption of the West's scientific and technological concepts and vocabulary. That is to say, what was once an exclusive possession of the West has now become the collective inheritance of the world. This is not new, for such has always been the case. What is now defined as "Western" is, in many ways, the result of an effective synthesis of past civilizations, especially those of the Jews, Greeks, and Romans.

The fifth manifestation is in the realm of military science and human warfare. Prior to the twentieth century, rulers lacked the capability to will the extinction of humanity. Today, the dangers of war have made it quite clear that there will be no victors in a thermonuclear war. It was this threat to human existence, ironically, that drove home the point to world leaders that the Cold War between capitalism and communism was detrimental to everyone. In retrospect, one can argue that one of the lessons learned from the Cold War is the fact that war can destroy all human societies. This global fear of extinction has become a thread of unity among those working energetically for peace in human communities around the world.

\section{Globalization as the Shortening of Distance}

In discussing how globalization can be conceptualized, one cannot ignore the revolution in human means of travelling. Globalization, in this context, is linked to the conquest of distance. Humanity has faced the challenge of distance for centuries. Since the Age of Discovery, when Portuguese caravels traveled from the seaport of Lagos on the southern tip of the Iberian peninsula to the West African coastline, individuals gradually have broken these barriers to greater human communication. Evidence for this claim that globalization has its historical roots in the Age of Discovery is provided by the fact that the world has changed dramatically since that time. Before Columbus came to the New World, 
Native Americans were unknown to the rest of the world. Certainly, those Europeans who encountered them in the fifteenth century had no room for them in their cosmological constructs. It was because of the absence of such a cosmological place and role for the Native Americans that the Europeans not only took their lands but also their lives. To add theological insult to physical injury, the conquistadors dismissed the target of their genocidal behavior as men and women without souls.

Two processes where taking place at this time when the physical barriers separating Europe from parts of the New World appeared to fall into European hands. The first was the expansion of the emerging capitalist world and the gradual incorporation of precapitalist societies into the world trading and commercial systems. This development did not augur well for the weak and powerless native peoples of the Americas and elsewhere. As history would have it, they soon became the victims and martyrs of the Age of Discovery. Their almost complete elimination was the painful result of this first step toward what is now known as globalization. The second process was the construction of a new hegemonic order that gradually transcended all societies through adopting and implementing new legal and moral codes in the state systems of the twentieth century. The United Nations' (UN's) Universal Declaration of Human Rights is a document whose emergence in world history rests primarily on the urgent need for moral order.

In retrospect, we can argue that the globalization of morality is the product of imperialism and colonialism. The successful colonization of the greater part of the planet by various European powers led to the creation of a new moral order. Some would call it the justice of the victor; others may argue that the only way humanity can be brought under one political roof is through imperialism or voluntary confederation and federation. The United States and Canada are two supreme models of greater human integration within a vast territory. The sense of belonging that exists within American society is largely due to the political, economic, and cultural integration of the American people.

The underlying idea of the UN was the attempt to globalize the moral sense of collective security, a noticeable failure of the inter-war period. Having seen the dreams of President Wilson turned into a nightmare by the triumph of Nazism in Germany, and hoping to preempt future holocausts, leaders and thinkers around the democratic and liberal world began to craft a new world order. The UN was conceived before the process of decolonization and thus, for this and other related reasons, at first denied the colonized people any representation. This situation would change only after the anticolonial movements of Asia and Africa gained momentum. It was due to this sea change in international politics that, 
within a few years, Africa accounted for more than one-third of all UN member countries.

The Muslim states of Africa and Asia also became a force to be reckoned with because of their rapid decolonization. But in examining the moral contents of the Declaration of Human Rights, one searches in vain for any reference to moral and religious concepts drawn from the Third World. This is one reason why UN-sponsored conferences on human rights in the early part of the 1990s triggered a controversy among certain African and Asian leaders. Muslims, Hindus, and Buddhists began to take issue with some of the leading concepts that have become pillars of the new world moral order. In their view, these concepts now paraded as human and international are to be treated with suspicion, for they were brought into existence largely through colonialism and imperialism.

In light of these arguments, one now can contend that the current globalization of morality is the beginning of a new world order in which the former colonizers and the inhabitants of their former colonies must construct an edifice that eventually will bear the fingerprints of all parties. This is the challenge facing the UN leadership. In order for us to live in a world where the globalization of morality has the same meaning for all people, there must be a feeling of belonging to this newly created moral world. Globalization will remain an empty slogan for the business world's corporate leaders if they and their political allies fail to recognize the need to involve all parties in constructing a planetary civilization built upon concepts and ideas from all parts of the world. Globalization will never be a reality if it bears the stamp of just one civilization.

It is undeniable that the West has contributed immeasurably to the development and enrichment of humanity, especially over the last five hundred years. However, if we truly are committed to building a genuinely human civilization with a morality that judges each and every human being by the content of his or her character, then political leaders and captains of commerce and industry must look into the possibility of incorporating those elements of humanity's diverse moral codes through emphasizing the points of convergence, not those of divergence. 